Journal of Current and Advance Medical Research

July 2017, Vol. 4, No. 2, pp. 36-39

http://www.banglajol.info/index.php/JCAMR

ISSN (Print) 2313-447X

ISSN (Online) 2413-323X

DOI: http://dx.doi.org/10.3329/jcamr.v4i2.36352

ORIGINAL ARTICLE

OPEN ACCESS

\title{
Clinico-demographic Characteristics of Pregnant Women with Diabetes Mellitus attended at a Referral Diabetic Care Hospital in Bangladesh
}

\author{
Shamsun Nahar ${ }^{1}$, Kashefa Khatun ${ }^{2}$, Tahamina Khanum ${ }^{3}$, Md. Masum Akther ${ }^{4}$, TA Chowdhury ${ }^{5}$, \\ AS Mohiuddin 6
}

${ }^{1}$ Junior Consultant (Gynaecology \& Obstetrics), Upazila Health Complex, Sonaimuri, Noakhali, Bangladesh; ${ }^{2}$ Associate Professor, Department of Gynaecology \& Obstetrics, Shaheed Suhrawardy Medical College, Dhaka, Bangladesh; ${ }^{3}$ Assistant Professor, Department of Gynaecology \& Obstetrics, Enam Medical College, Savar, Dhaka, Bangladesh; ${ }^{4}$ Assistant Professor, Department of Gynaecology \& Obstetrics, Abdul Malek Ukil Medical College, Noakhali, Bangladesh; ${ }^{5}$ Professor, Department of Gynaecology \& Obstetrics, Bangladesh Institute of Research and Rehabilitation for Diabetes, Endocrine and Metabolic Disorders, Dhaka, Bangladesh; ${ }^{6}$ Professor \& Head, Department of Radiology \& Imaging, Bangladesh Institute of Research and Rehabilitation for Diabetes, Endocrine and Metabolic Disorders, Dhaka, Bangladesh

[Reviewed: 30 February 2017; Accepted on: 1 April 2017; Published on: 1 July 2017]

\section{Abstract}

Background: The clinical and demographic profiles of pregnant women with diabetes mellitus are very important consideration during management. Objectives: The purpose of the present study was to see the clinico-demographic characteristics of pregnant women with diabetes mellitus attended at a referral diabetic care hospital in Bangladesh. Methodology: This cross sectional study was carried out in inpatient Department of Obstetrics and Gynecology and in outpatients Department of Radiology and Imaging of Bangladesh Institute of Research and Rehabilitation for Diabetes, Endocrine and Metabolic Disorders (BIRDEM) at Dhaka, Bangladesh during the period of April 2005 to March 2007 for a period of two (02) years. Pregnant women diagnosed as diabetes mellitus or gestational diabetes mellitus (GDM) selected for caesarean section or induction of labour, gestational age 236 weeks having 23700 gm by clinical method were included in this study. All the clinical relevant data and demographic characteristics were recorded. Result: A total number of 69 pregnant women with diagnosed DM or GDM were recruited for this study. The mean $( \pm \mathrm{SD})$ age of the patients was $30.8 \pm 5.1$ years ranged from 20 to 40 years. $60.9 \%$ patients were from middle socioeconomic class, $30.4 \%$ from low and $8.7 \%$ from high class. $58.0 \%$ had DM and $42.0 \%$ had GDM. The mean (1SD) gestational age of the patients was 37.511 .5 weeks range from 36 to 41 weeks. Conclusion: In conclusion majority of the pregnant women are in the middle age group with the middle income group. [Journal of Current and Advance Medical Research 2017;4(2):36-39.]

Keywords: Clinical profiles; demographic Characteristics; Pregnant Women; Diabetes Mellitus; Gestational diabetes mellitus

Correspondence: Dr. Shamsun Nahar, Junior Consultant (Gynaecology \& Obstetrics), Upazila Health Complex, Sonaimuri, Noakhali, Bangladesh; Email: drsweety.nahar@gmail.com; Cell no.: +8801775339803

Cite this article as: Nahar S, Khatun K, Khanum T, Akther MM, Chowdhury TA, Mohiuddin AS. Clinico-demographic Characteristics of Pregnant Women with Diabetes Mellitus attended at a Referral Diabetic Care Hospital in Bangladesh. Journal of Current and Advance Medical Research 2017;4(2):36-39

Conflict of Interest: All the authors have declared that there was no conflict of interest.

Funding: This research project was not funded by any group or any institute on.

Contributions to authors: Nahar S, Mohiuddin AS \& Khatun K have contributed in protocol preparation up to procedures as well as the report writing; Khanum T, Akther MM \& Chowdhury TA have written the manuscript and have revised the manuscript.

Copyright: (92017 Nahar et al. Published by Journal of Current and Advance Medical Research. This article is published under the Creative Commons CC BY-NC License (https://creativecommons.org/licenses/by-nc/4.0/). This license permits use, distribution and reproduction in any medium, provided the original work is properly cited, and is not used for commercial purposes. 


\section{Introduction}

Diabetes mellitus is an important medical disorder during pregnancy and it creates substantial risk for both the mothers and fetus ${ }^{1}$. It is a clinical syndrome characterized by deficiency of or insensitivity to insulin and exposure of organs to chronic hyperglycemia, is the commonest medical complication in pregnancy $^{2}$. Abnormalities of carbohydrate metabolism occur frequently during pregnancy and between $1.0 \%$ and $3.0 \%$ of all pregnant patients show glucose intolerance ${ }^{3}$. The largest number of these patients is comprised of individuals with genetic or metabolic predisposition towards diabetes and who 'are incapable of compensating adequately for the diabetogenic effects of pregnancy, that is, patients with gestational diabetes. A smaller group is formed by women who had diabetes diagnosed before they became pregnant ${ }^{1}$.

Diabetes mellitus (DM) complicating pregnancy may be classified as presentational DM and gestational $\mathrm{DM}^{4}$. Diabetes diagnosed prior to pregnancy which is known as presentational diabetes, affects approximately 1 to 3 pregnancies per 1000 birth $^{5}$. Many women come for medical care for the first time during pregnancy. Gestational diabetes mellitus (GDM) is defined as glucose intolerance that has its onset or first recognition during pregnancy and it complicates approximately 3 to $4 \%$ of pregnancies ${ }^{2}$. The clinical profiles and demographic characteristics are essential to manage these cases. Thus this present study was undertaken to see the clinicodemographic characteristics of pregnant women with diabetes mellitus attended at a referral diabetic care hospital in Bangladesh.

\section{Methodology}

This was a cross sectional study. The study was carried out in the department of Obstetrics and Gynecology, BIRDEM in collaboration with the department of Radiology and Imaging department of the same institute. The study was carried out for a period of two years from April 2005 to March 2007. Prior to the commencement of this study, the research protocol was approved by the Local Ethical Committee of BIRDEM Academy. Pregnant women with pre-gestational and gestational diabetes mellitus having fasting blood sugar level $26.1 \mathrm{mmol} / \mathrm{l}$ aged from 20 to 40 years and gestational age 36 weeks admitted in inpatient Department of Obstetrics and Gynecology, BIRDEM, Dhaka and attending in outpatient Department of Radiology and Imaging of the same institute are selected as subjects. Non-randomized consecutive sampling was used to collect the data. Pregnancy of 36 weeks with diagnosed pregestational DM and GDM having fasting blood sugar level $26.1 \mathrm{mmol} / \mathrm{L}$ as per WHO Expert Committee 1999 selected for caesarean section or induction of labour, accurate gestational age regular menstrual cycle with exact last menstrual period and having early ultrasonography, longitudinal lie, cephalic presentation, intact membranes and estimated fetal weight $23700 \mathrm{gm}$ by clinical method were included as study population $^{3}$. Pregnancy less than 36 weeks, pregnancy with pregestational DM or GDM with complication like hypertension, ketoacidosis, presence of uterine tumour, ruptured membranes, malpresentation, multiple pregnancy were excluded from this study. Those who were agreed to take part in this study were selected. Written consent was taken from the patients. Then detailed history was taken and clinical examination was done and those who were clinically macrosomic were sent for ultrasonographic estimation of the fetal weight. Once the babies were born, their actual birth weights were measured by Weight machine. All the information were recorded in a pre-designed data collection sheet.

\section{Results}

A total number of 69 pregnant women with diagnosed DM or GDM selected for caesarean section or induction of labour, gestational age 36 weeks having $23700 \mathrm{gm}$ by clinical method were included in this study. Our targeted sample size was 73 and 1 collected 73 cases. Out of these, 4 cases were dropped due to delivery in other hospital. Finally 69 pregnant women were studied. The mean age of the study subjects was 30.8 years with standard deviation 5.1 years and ranged from 20 to 40 years. The maximum pregnant woman was found between 26 to 30 years age range and minimum was found between 36 to 40 years age range (Table 1).

Table 1: Age distribution of the study subjects $(\mathbf{n}=69)$

\begin{tabular}{|l|c|c|}
\hline Age Group & $\begin{array}{c}\text { Frequenc } \\
\text { y }\end{array}$ & Percentage \\
\hline $\mathbf{2 0}$ to 25 Years & 27 & 39.1 \\
\hline $\mathbf{2 6}$ to 30 Years & 30 & 43.5 \\
\hline 31 to 35 Years & 8 & 11.6 \\
\hline 36 to 40 Years & 4 & 5.8 \\
\hline Total & $\mathbf{6 9}$ & $\mathbf{1 0 0 . 0}$ \\
\hline Mean \pm SD & $30.8 \pm 15.1$ (years) \\
\hline
\end{tabular}


Most of the study subjects came from low and middle socio-economic class (Table 2).

Table 2: Socio-economic conditions of the subjects $(n=69)$.

\begin{tabular}{|l|c|c|}
\hline $\begin{array}{l}\text { Socio-Economic } \\
\text { Class }\end{array}$ & Frequency & Percentage \\
\hline Low & 21 & 30.4 \\
\hline Middle & 42 & 60.9 \\
\hline High & 6 & 8.7 \\
\hline Total & $\mathbf{6 9}$ & $\mathbf{1 0 0 . 0}$ \\
\hline
\end{tabular}

The study group showed that maximum subject had DM (58.0\%) and 42.0\% had GDM (Table 3).

Table 3: Distribution according to clinical features $(n=69)$

Types of Frequency Percentage

Diabetes

\begin{tabular}{|l|c|c|}
\hline DM & 40 & 58.0 \\
\hline GDM & 29 & 42.0 \\
\hline Total & $\mathbf{6 9}$ & $\mathbf{1 0 0 . 0}$ \\
\hline
\end{tabular}

$Z$ value $=1.90, p>0.05$ in $Z$ test

The mean $( \pm \mathrm{SD})$ gestational age of the subjects was $37.5+1.5$ weeks and ranged from 36 to 41 weeks. Highest $(39.1 \%)$ percentage was found in 37 weeks of gestation and lowest (4.3\%) was in 41 weeks of gestation (Table 4).

Table 4: Distribution of gestational age $(n=69)$

\begin{tabular}{|l|c|c|}
\hline $\begin{array}{l}\text { Gestational } \\
\text { Age }\end{array}$ & Frequency & Percentage \\
\hline 36 weeks & 16 & 23.2 \\
\hline 37 weeks & 27 & 39.1 \\
\hline 38 weeks & 10 & 14.5 \\
\hline 39 weeks & 9 & 13.0 \\
\hline $\mathbf{4 0}$ weeks & 4 & 5.8 \\
\hline $\mathbf{4 1}$ weeks & 3 & 4.3 \\
\hline Total & $\mathbf{6 9}$ & $\mathbf{1 0 0 . 0}$ \\
\hline Mean+SD & $37.5 \pm 1.5$ & \\
\hline
\end{tabular}

\section{Discussion}

The dramatic increase in the prevalence of GDM and its adverse maternal and neonatal complications may possibly be reduced by controlling the risk factors involved in the development of $\mathrm{GDM}^{4}$. According to the present study the high risk factors of GDM were advanced maternal age, increased BMI, parity, family history of diabetes and previous history of gestational diabetes $^{5-8}$. Diabetes mellitus during pregnancy is an important part of obstetrics ${ }^{2}$. Accurate estimation can help in deciding the timing and mode of delivery of the fetuses. An accurate diagnosis of the condition of the fetus can lead to a decrease in perinatal morbidity ${ }^{5}$. Its prediction may enable the physician and staff to prepare for shoulder dystocia or prevent a traumatic injury ${ }^{6-7}$.

The present study findings were discussed and compared with previously published relevant studies. In this study mean $( \pm \mathrm{SD})$ age of the patients were $30.8 \pm 15.1$ years, most of them were from middle socio-economic class, maximum had DM and highest percentage was found in 3 weeks of gestation.

In this study the mean $( \pm \mathrm{SD})$ gestational age of the subjects was $37.5+1.5$ weeks and ranged from 36 to 41 weeks. Highest (39.1\%) percentage was found in 37 weeks of gestation and lowest (4.3\%) was in 41 weeks of gestation.

The mean age of the study subjects was 30.8 years with standard deviation 5.1 years and ranged from 20 to 40 years. The maximum pregnant woman was found between 26 to 30 years age range and minimum was found between 36 to 40 years age range. Azim et $\mathrm{al}^{6}$ have reported that majority $(81.92 \%)$ of the patients were below 30 years of age, $78.31 \%$ belonged to middle socioeconomic group.

In this study almost $58.0 \%$ women had education below SSC level and $28.91 \%$ took regular antenatal checkup. About $61.45 \%$ patients were multigravida. Most $(59.04 \%)$ ante-partum deaths were identified below 32 weeks of pregnancy. The association between GDM and socioeconomic status is less well established, with conflicting results seen in previous studies ${ }^{8-11}$. These studies cannot easily be compared because of different definitions of social status used, depending upon monthly income, educational attainment, employment, family influence, type of health care and house hold characteristics.

\section{Conclusions}

In conclusion majority of the pregnant women are in the middle age group. Most of them are coming from the middle income group family. Furthermore the women with previous history of Diabetes mellitus are the most common than gestational diabetes mellitus. As the study was conducted with a small number of subjects, further study may be undertaken in future with large number of subjects. 


\section{References}

1. Janzen C, Greenspoon J, Palmer SM. Diabetes Mellitus in Pregnancy. In: DeCherney AH, Nathan L (eds), Current Obstetrics and Gynecologic Diagnosis and Treatment, 9*h edn, Mc Graw Hill, New York 2003; pp. 326-37

2. Gilmer MDG and Hurley PA. Diabetes and endocrine disorders in pregnancy. In: Edmonds DK (ed), DeWhaurst's Text Book of Obstetrics and Gynaecology for Post graduates, $6^{\text {th }}$ edn, Blackwell science, London 1999; pp. 197-09.

3. McCormick $M$ (editor). Integrated Management of Pregnancy and Child birth, World Health Organization 2000;C61:27.

4. Landon MB. Diabetes Mellitus and other endocrine disease. In: Gabbe SG, Niebyl IR, Simpson IH (eds), Obstetrics (Normal and problem pregnancies), $3^{\text {rd }}$ edn, Churchill Livingstone, London 1996; pp. 1036-81

5. Wild S, Roglic G, Green A, Sicree R and Hilary K. Global Prevalence of Diabetes. Diabetes Care 2004;27:1047-53
6. Azim MA, Sultana N, Chowdhury S, Azim E. Maternal sociodemographic characteristics and risk factors of antepartum fetal death. Mymensingh medical journal: MMJ. 2012;21(2):322-6

7. Khan R, Ali K, Khan Z. Socio-demographic risk factors of Gestational Diabetes Mellitus. Pakistan journal of medical sciences. 2013;29(3):843

8. Kim C, Newton KM, Knopp RH. Gestational diabetes and the incidence of type 2 diabetes. Diabetes Care. 2002;25:1862-1268

9. Dabelea D, Snell-Bergeon JK, Hartsfield CL, Bischoff KJ, Hamman RF, McDuffie RS. Increasing prevalence of gestational diabetes mellitus over time and by birth cohort. Diabetes Care. 2005;28:579-584

10. Ben-Haroush A, Yogev Y, Hod M. Epidemiology of gestational diabetes mellitus and its association with type 2 diabetes. Diabet Med 2004;21:103-113

11. Metzger BE, Gabbe SG, Persson B. International association of diabetes and pregnancy study groups recommendations on the diagnosis and classification of hyperglycemia in pregnancy. Diabetes Care 2010;33:676-682 